\title{
Comparing Environmental Attitudes and Behaviors between an Indigenous and a Non-indigenous Sample from New Zealand and the United States of America
}

\author{
Anthony Snider \\ Department of Environmental Sciences, University of North Carolina at Wilmington \\ 601 South College Road, Wilmington, NC 28403, USA \\ Tel: 910-962-2423Ｅ-mail: snidera@uncw.edu \\ Shanhong Luo (Corresponding author) \\ Department of Psychology, University of North Carolina at Wilmington \\ 601 South College Road, Wilmington, NC 28403, USA \\ Tel: 910-962-7904Ｅ-mail: luos@uncw.edu
}

Theresa Schell

Department of Environmental Sciences, University of North Carolina at Wilmington 601 South College Road, Wilmington, NC 28403, USA

E-mail: schell.theresa@gmail.com

Jeffery Hill

Department of Environmental Sciences, University of North Carolina at Wilmington 601 South College Road, Wilmington, NC 28403, USA

Tel: 910-962-3264Ｅ-mail: hillj@uncw.edu

Received: October 14, 2020 Accepted: November 4, 2020 Published: November 19, 2020 doi:10.5296/emsd.v10i1.17820 URL: https://doi.org/10.5296/emsd.v10i1.17820 


\section{Abstract}

While there has been a substantial amount of literature published on environmental beliefs and behaviors, cross-cultural research in this area, particularly comparisons between indigenous vs. non-indigenous people, remains limited. The current study conducted a comparison of the environmental beliefs and behaviors, as well as political attitudes, between an indigenous and a non-indigenous sample of New Zealand and the US (total $n=322$ ). Respondents included students at the University of Waikato in New Zealand (Māori and European New Zealanders) and the University of North Carolina Pembroke in the US (Lumbees and non-indigenous Americans). The participants provided responses regarding their ecological worldview, belief in global climate change, and participation in environmentally responsible behaviors as well as their political attitudes, including system justification and political liberalism. Results showed that the New Zealand sample was more politically liberal and demonstrated more environmentally friendly beliefs and behaviors than the US sample. The indigenous group did not differ in their environmental beliefs or behaviors from their non-indigenous counterpart, but did endorse less system justification. Mediation analyses indicated that ecological worldview and belief in global climate change together fully mediated the link between political liberalism and environmentally responsible behavior. Implications of these findings for environmental behavior research and education are discussed.

Keywords: Indigenous group, Cross-cultural, Environmental belief, Environmental behavior, Political ideology, System justification

\section{Introduction}

Over the last century, environmental problems have rapidly become some of most pressing global concerns; transcending national, ethnic, and cultural boundaries. Addressing these problems requires international, collective efforts, necessitating a better understanding of environmental beliefs and behaviors in all cultures. While there has been a substantial body of literature on environmental beliefs and behaviors (see Bamberg \& Moser, 2007; Hines, Hungerford, \& Tomera, 1987 for meta-analyses), cross-cultural research in this area, particularly comparisons between indigenous vs. non-indigenous peoples, remains limited (see Cowie, Greaves, Milfont, Houkamau, \& Sibley, 2016). In light of this limitation, the current study was designed to conduct a comparison of the environmental beliefs and behaviors between an indigenous and a non-indigenous sample from New Zealand (NZ) and the US.

One focus of environmental research seeks to explain why people adopt certain environmental beliefs and behaviors. Political ideology has been identified as one of the most consistent predictors of environmental belief and behavior (see Dunlap, Xiao, \& McCright, 2001; Hornsey, Harris, Bain, \& Fielding, 2016). Additionally, recent research indicates system justification (i.e., acceptance of the societal status quo) is a key mechanism that helps explain why political ideology is such an important predictor (Feygina, Jost, \& Goldsmith, 2010). We believe that system justification is a uniquely relevant dimension in the comparison of indigenous and non-indigenous groups given the history and contemporary 
status of indigenous groups in extant political systems, whereas comparing the political ideology between New Zealanders and Americans is particularly interesting considering the differences in political climate between these two nations. In addition to examining ethnic and national differences in political ideology and system justification, the current study also aimed to test the associations among political attitudes, environmental beliefs and behaviors.

\subsection{Environmental Beliefs and Behaviors}

Environmental researchers have long been interested in understanding people's environmental beliefs and behaviors. In the current research, we chose to assess environmental beliefs both at a broad level as a worldview reflected in Dunlap, Van Liere, Mertig, and Jones's (2000) revised New Ecological Paradigm (NEP) and at a specific level captured by belief in global climate change (GCC). In assessing environmentally responsible behaviors (ERB), we followed Sivek and Hungerford's (1989/1990) definition that focuses on actions of a group or individual advocating the sustainable use of natural resources. We selected typical environmental behaviors primarily according to the natural resources affected by those behaviors (e.g., water, electricity).

\subsubsection{New Ecological Paradigm}

The Revised NEP by Dunlap et al. (2000) is a revision of Dunlap and Van Liere's (1978) original New Environmental Paradigm. Whereas the original NEP focused on environmental concerns, the revised NEP taps a much broader ecological worldview based on the endorsement of a range of environmental beliefs. Individuals who espouse the NEP tend to believe that (1) humans, just like many other species, are interdependently involved in the global ecosystem; (2) the environment is neither indestructible nor unlimited in resources; (3) human activities have a strong impact on the environment and are also constrained by the environment (e.g., Dunlap et al., 2000; Xiao, Dunlap, \& Hong, 2019).

Previous research has established a reliable, positive association between NEP and pro-environmental behavior (e.g., Boiral, Raineri, \& Talbot, 2018; Cordano, Welcomer, \& Scherer, 2003). The NEP has also been used in a variety of populations that differ in nationality (e.g., Furman, 1998; Gooch, 1995; Pierce et al., 1987; Wiidegren, 1998), ethnicity (Caron, 1989; Noe \& Snow, 1990), and age (Bechtel, Verdugo, \& Pinheiro, 1999; Schultz \& Zelezny, 1998). For example, Johnson, Bowker, and Cordell (2004) compared four minority ethnic groups' NEP scores to those of Whites' in a nationally representative dataset from the US. Their finding indicated that whereas African-American and foreign-born Latinos were less similar to Whites in their NEP and ERB, Asian-American and US-born Latinos were quite similar to Whites.

\subsubsection{Belief in Global Climate Change}

Global climate change is arguably the most salient environmental issue currently being discussed in the US. Fully 97\% of scientists believe in anthropogenic climate change (Cook et al., 2013), and recent research indicates that $70 \%$ of Americans now believe climate change is happening and 58\% believe it is mostly human-induced (Leiserowitz et al., 2018). This is a marked increase from earlier assessments revealing that only 54-65\% of Americans 
believe in climate change (e.g., Hornsey et al., 2016; Leiserowitz, Maibach, Roser-Renouf, \& Hmielowski, 2012). Although belief in GCC is a very specific issue and much narrower in scope than the NEP, it has been shown to play an important role in predicting environmental behaviors due to the high salience of GCC. A meta-analysis by Hornsey et al. (2016) showed that GCC belief by itself has a small to moderate effect on pro-environmental intentions and actions. We thus predict that even though GCC is a specific belief, it will make a significant contribution in predicting ERB independent of NEP.

\subsection{Political Attitudes}

\subsubsection{Political Ideology}

Throughout the literature, political ideology is repeatedly found to be a strong predictor of environmental awareness, concerns, attitudes, values, and beliefs (e.g., Buttel \& Flinn, 1978; Dunlap et al., 2000; Xiao \& McCright, 2007). A review by Dunlap et al. (2001) concluded that nearly all relevant studies have found that politically liberal individuals score higher on measures of environmental concern than their conservative counterparts. Studies that relate political attitudes to environmental behaviors also report that liberalism is positively associated with ERB (e.g., Mobley et al., 2010; Olli, Grendstad, \& Wollebaek, 2001; Snider, Luo, \& Fucso, 2018). An important rationale for the apparent divergence between liberals and conservatives in environmental attitudes and behaviors is that environmental protection requires government interference and social changes, which are acceptable to liberal, while the conservatives tend to favor a free-enterprise mindset, and hence limited (laissez-faire) government as well as resistance to social change (Dunlap et. al., 2001).

\subsubsection{System Justification}

System justification refers to the belief that current system is fair and just; requiring no change in the status quo. According to system justification theory, human beings have epistemic, existential, and relational needs to maintain a sense of certainty, stability, and safety (Jost \& Hunyady, 2005; Jost, Ledgerwood, \& Hardin, 2008). These needs give rise to a motivation to perceive the system as fair and legitimate, as well as a desire to protect the status quo (Jost, Liviatan, et al., 2009). System justification has been theorized as a psychological mechanism that may explain why some people, particularly conservatives, deny environmental problems and resist pro-environmental actions. For these individuals, acknowledging environmental issues threatens the foundations of the social, economic, and political status quo; whereas addressing these environmental issues calls for changes in prevailing social practices, industrial processes, and political agendas (Feygina et. al., 2010). Therefore, the more one endorses the status quo and believes in system justification, the less likely one would accept and act on pro-environmental ideology.

The present study included both political ideology and system justification in order to accomplish two goals: (1) to compare these political attitudes in New Zealander and US samples, including both indigenous and non-indigenous groups; and (2) to examine how these two related factors contribute to the prediction of environmental beliefs and behaviors. In light of previous research, we hypothesized that these two political attitudes will both 
predict environmental beliefs, specifically NEP and GCC; these environmental beliefs, in turn, will lead to ERB. In other words, NEP and GCC are expected to act as a mediator between the links between political attitudes and ERB.

\subsection{Indigenous vs. Non-indigenous Cultures}

Culture serves as a means to address the issue of humans' relationship with the natural environment (see Milfont \& Schultz, 2016; Ponting, 1991). Due to the perception that their lifestyles tend to involve a more intimate relationship with the natural environment, indigenous cultures may embrace more eco-centric values and holistic worldviews, despite globalization and gradual erosion of their traditions when compared to non-indigenous societies (e.g., Hawke, 2012; Michell, 2005; White, 2010). However, empirical comparisons between indigenous and non-indigenous groups' environmental beliefs and actions are scarce. An important new contribution of the current study was to compare two specific indigenous groups (Māori and Lumbee) from two different nations and continents to their non-indigenous counterparts in environmental beliefs, behaviors, and political attitudes.

Māori are the indigenous peoples of New Zealand. Traditional Māori beliefs and teachings contain fundamental themes of environmentalism. According to the Māori creation story, human life resulted from the embrace of Ranginui, the Sky Father, and Papatuanuku, the Earth Mother (see Roberts, Norman, Minhinnick, Wihongi, \& Kirkwood, 1995). Because humans are a product of nature, Māori see nature as an integral part of whakapapa (genealogy) that should be taken care of for future generations (Rangihau, 1992). The importance of whakapapa is highly stressed within the Māori culture (Marsden \& Henare, 1992). People's deep kinship with nature is expressed through kaitiakitanga, which is an ideology of conservation and guardianship. Traditional kaitiakitanga practices include environmentally sustainable behaviors such as rähui: periods when no one may take any resources or particular resources (such as shellfish) from an area. Practices also include other forms of tapu (restriction) to prevent mauri (life force) from being degraded (e.g., limiting the size of the species people may take or the amount of their total catch) (Hutching \& Walrond, 2007). These cultural values and practices cultivate an ecological ideology that encourages Māori to be aware of and respectful of the environment and nature (Rangihau, 1992). Indeed, NZ national data show that Māori express the highest levels of regard for the environment of all ethnic groups in the country (Cowie et al., 2016). Māori are also more likely to report involvement in pro-environment behaviors than European New Zealanders and other ethnicities do (Hughey, Kerr, \& Cullen, 2016; Kerr, Hughey, \& Cullen, 2016).

Similarly, American Indians, the indigenous people of America such as the Lumbees, also had a close relationship with the physical environment before European contact. They lived in relatively small dwellings and were keenly aware of ecological rhythms and resources. American Indians defined themselves by the land, and honored certain parts of nature as sacred. They celebrated the earth's fruits and gave thanks for the resources they used. American Indians did alter the landscape, yet they managed to do so based on years of accumulated wisdom passed down from generations of trial and error (Lewis, 1995). The purported "Ecologically Nobel Savage" stereotype portrays indigenous American Indians as 
age-old stewards of the earth, characterized by their ecological wisdom, spiritual connections with the land, and harmonious relationship with the environment (Redford, 1991); although this stereotype has been criticized as being oversimplified and potentially inaccurate (Nadasdy, 2005).

Since first European contact, indigenous peoples throughout the world have experienced a long history of colonization. Their traditional lifestyles have been greatly altered due to cultural suppression using both formal government policies and informal practices (for Māori see O'Regan, 2012; Roberts et al., 1995; Williams, 2001; for American Indians see Hoxie, 1984; McDonnell, 1994; Prucha, 1984). Indigenous political, cultural, material, environmental rights are inextricably intertwined. Fighting for these rights has become a perpetual struggle for indigenous groups. This is evident in Cowie et al.'s (2016) finding that Māori's sociopolitical consciousness (i.e., the extent to which participants recognize the importance of Māori political rights and stand up for them) was the only significant predictor of higher environmental regard out of a dozen of demographic and value variables, suggesting that environmental regard is a central tenet of Māori political aims. Likewise, Clark (2002) argued that American Indian movements have the potential to be effective in bringing about environmental change, as these groups are able to break down the distinction between environmental issues and issues regarding sovereignty, capitalism, and colonization. Thus, we expect that the indigenous sample will be less likely to endorse system justification, but more likely to be environmentally friendly in both beliefs and actions compared to their non-indigenous counterpart.

\subsection{New Zealand vs. the United States}

When NZ was first settled by Europeans, the land was depicted as a consumable paradise. Over the past few decades, NZ has actively promoted its "clean and green" image of a distant utopia to the world. A key component of this promotion began in the mid-1980s as the country passed a national ban on nuclear energy. The ban was quickly integrated with broader environmental issues with strong cultural resonance that provide a great sense of national pride for New Zealanders. Furthermore, there are significant economic benefits associated with this image. With tourism and agriculture being two primary industries in NZ, the country's economic well-being relies heavily on the natural environment (Coyle \& Fairweather, 2005). Because NZ's clean, green image is widely supported, the public has a high regard for the environment and tends to enthusiastically act upon it. For example, New Zealanders rate the quality of the natural environment as being the third most important goal, only behind quality of life and the quality of education (Growth and Innovation Advisory Board, 2004). According to a recent survey, more than $70 \%$ of NZ respondents recycle household waste, buy products marketed as environmentally friendly, reduce or limit their use of electricity, compost garden or household waste, or grow some of their own vegetables (Hughey et al., 2016). As a result, New Zealanders gave higher ratings to NZ's environment compared to other developed nations (Hughey et al., 2016).

Similar to NZ, the US was presented as an earthly paradise during its period of early contact with the Western world. Myths of the New World included a focus on material and sensual 
attributes of nature, such as fabulous resources and garden-like natural beauty (Nash, 2001). However, unlike NZ, the US is not considered to be one of the most "green" or coherently environmentally responsible nations as a whole when examined in objective measures of environmental performance. For example, the Environmental Performance Index, the most widely cited source of comparable international data used to compare across nations, ranked NZ $11^{\text {th }}$ and the US 26 ${ }^{\text {th }}$ in 2016 (Hsu et al., 2016). Notably, the US announced in 2017 that it will be the first nation to withdraw its participation in the Paris Climate Agreement. Therefore, we expect that New Zealanders will show a higher endorsement of environmental attitudes as well as more active engagement in ERB than Americans.

Politically, the US has a dichotomous political system, with a distinct gap between liberals and conservatives on many critical issues, including support for environmental efforts, particularly between Democrats and Republicans in Congress (Dunlap et al., 2001; Hornsey, Harris, \& Fielding, 2018). This gap has increasingly widened since the 1970s (Dunlap et al., 2001) and has been heightened in recent political events such as the 2008 and 2016 Presidential elections (Hawkins, Yudkin, Juan-Torres, \& Dixon, 2018). On several key social-political issues typically regarded as signs of a liberal society, such as abortion rights, gun control, racial tension, and immigration, the US has not shown significant progress. In contrast, NZ is considered one of the more open and progressive nations in the world. For example, NZ was the first nation to give women the right to vote in 1893 (the US did so in 1920) and legalized gay marriage two years before the US did. Thus, we expect the US sample as a whole to be less liberal than the NZ sample.

\subsection{Current Study}

To recapitulate, while there has been substantial research on environmental beliefs and behaviors, particularly the antecedents to them such as political ideology, much less has been undertaken on cross-cultural investigations, and little on comparisons of indigenous and non-indigenous groups. The first goal of the current study was to conduct a comparison between the NZ and US samples as well as a comparison between the indigenous and non-indigenous samples in political and environmental attitudes and behaviors. Based on the literature review, we propose the following hypotheses:

H1: The NZ sample will report more liberal attitudes, more environmentally friendly beliefs, and more ERB than the US sample.

H2: The indigenous sample (i.e., Māori and Lumbee) will report less system justification, more environmentally friendly beliefs, and more ERB than their non-indigenous counterpart.

The second goal of the current study was to examine the associations between political attitudes (liberalism and system justification) and environmental beliefs and behaviors. In an attempt to replicate and extend previous findings, we propose the following mediation model:

H3: Environmentally friendly beliefs (NEP and GCC) will mediate the associations between political attitudes (liberalism and system justification) and ERB. 


\section{Method}

\subsection{Participants and Procedure}

The participants of this study were recruited from the University of Waikato in Hamilton, New Zealand and the University of North Carolina at Pembroke (UNCP) in the United States. This study received approval from the IRB committee at all three participating institutions: University of Waikato, UNCP, and University of North Carolina at Wilmington. The University of Waikato has a student population of approximately 12,500 students. It works closely with iwi (Māori tribes), particularly the Tainui, to make the university accessible to Māori students. The Māori population enrolled at Waikato is $19 \%$ of the total student population (Waikato University, 2012). UNCP has a student population totaling approximately 6,300 (UNCP College Portrait, 2012). The university is located in Robeson County, which is the center of the Lumbee Tribe. The Lumbee is North Carolina's largest American Indian tribe and is fully recognized as Indian by the State of North Carolina, and partially recognized by the United States Federal Government (Lumbee Tribe of North Carolina, 2012). American Indians comprise 16\% of students at UNCP (UNCP College Portrait, 2012).

At the University of Waikato, upon instructor approval, a survey was administered in the first or last fifteen minutes of Tikanga Māori (Māori Cultural Studies) and Geography classes. The same procedure was followed at UNCP, where the surveys were administered in Native American Studies, Sociology, Cultural Anthropology, and Earth Science classes. With the exception of the Māori Cultural Studies and the Native American Studies classes, the classes were all entry-level courses in order to achieve a sample of a variety of majors on each campus who had yet to be exposed to a considerable amount of environmental education. All participants were provided written information that participation in this study was completely voluntary and they could refuse to participate and may withdraw anytime should they decide to participate. No incentive was provided for the participants. The surveys were stored and analyzed in the laboratory of the second author.

The total number of participants was 343, including 140 males, 202 females, and 1 participant who did not to report gender. The average age of the entire sample was 21.98 years $(S D=7.16)$. The NZ sample comprised 125 respondents, including 49 indigenous (i.e., Māori), 74 non-indigenous individuals, and 2 with no specification of ethnicity. The US sample had 197 participants, including 41 indigenous (i.e., American Indian), 155 non-indigenous individuals, and 1 with no specification of ethnicity. Another 21 participants were neither NZ nor US citizens. They were excluded from analyses that required nationality identification but included in the correlation and mediation analyses. The NZ and US samples did not differ significantly in age, education level, or household income. They did show a significant difference in religion $\left(X^{2}(14)=81.91, p<.01\right)$. While the US sample was predominantly ( $83 \%$ ) Christian, only $39.2 \%$ of the NZ sample was Christian; the NZ sample had much higher percentages endorsing atheist (12.7\%), undecided (23.5\%), and other (15.7\%) compared to the US sample (10.1\% with all these options combined). 


\subsection{Measures}

\subsubsection{Demographics}

The survey included questions such as age, sex, major, nationality, ethnicity, religion, education, income, etc. For ethnicity, participants were asked to indicate their specific ethnic background (e.g., specific tribe name), which was later coded as either indigenous (i.e., Māori or American Indian) or non-indigenous (i.e., any other ethnicity) for analysis.

\subsubsection{New Ecological Paradigm}

The Revised New Ecological Paradigm (NEP) was used to measure the respondents' environmental beliefs (Dunlap et al., 2000). The NEP includes five dimensions of an ecological worldview: the reality of limits to growth (e.g., "We are approaching the limit of the number of people the earth can support"), antianthropocentrism (e.g., "Plants and animals have as much right as humans to exist"), the fragility of nature's balance (e.g., "The balance of nature is very delicate and easily upset"), rejection of exemptionalism (e.g., "Despite our special abilities humans are still subject to the laws of nature"), and the possibility of an eco-crisis (e.g., "Humans are severely abusing the environment"). Each dimension is measured with three items. Participants responded to this scale with a 5-point Likert scale ranging from 1 ("disagree strongly") to 5 ("agree strongly"). The alpha reliability was .74. The average was computed across the 15 items such that a higher score indicated a more pro-ecological worldview.

\subsubsection{Global Climate Change Belief}

This was measured by two items: "I believe global climate change is real" and "I believe global climate change is primarily caused by humans." Participants responded to this scale with a 5-point Likert scale ranging from 1 ("disagree strongly") to 5 ("agree strongly"). The alpha reliability was .65. The average was computed across the 2 items such that a higher score indicated a more pro-ecological belief.

\subsubsection{System Justification}

The system justification measure was adopted from Kay and Jost (2003). It contains eight items, using a 9-point response scale ranging from 1 (disagree strongly) to 9 (agree strongly). A sample item is "In general, the American political system operates as it should." The scale was modified slightly to allow it to be applicable in NZ. A high score on this scale indicates that the individual is more likely to justify and support the current system that they live in. The alpha reliability was .71 .

\subsubsection{Political Ideology (Liberalism)}

Participants indicated whether they agreed or disagreed with nine statements reflecting a range of contemporary socio-political issues such as the legalization of abortion, public school prayer, the censorship of pornography, and the legalization of same-sex marriages (see Luo, 2009). Participants responded with a 5-point scale: 1-disagree strongly, 2-disagree a little, 3-neither agree or disagree, 4-agree a little, and 5-agree strongly. The alpha reliability 
was .72. We computed an average over the items such that high scores reflected more liberal attitudes.

\subsubsection{Environmentally Responsible Behaviors}

To ensure our measure of specific ERB was comprehensive, we started with Smith-Sebasto and D' Costa's (1995) approach and included a large pool of a wide range of 100 behaviors. We also followed Hawthorne and Alabaster's (1999) approach and grouped the behaviors primarily according to the natural resources affected (e.g., water, electricity) with the addition of a final category of "environmental activism." Thus, the 100 ERB represent six categories: water consumption, energy consumption, material consumption, waste disposal, general ecological footprint reduction, and activism and knowledge (See Snider et al., 2018). Due to the survey space limit, we shortened this measure to a total of 17 items by selecting two or three items from each category that were most applicable to college students. Sample items are "I sorted glass, cans, plastic, or papers for recycling" and "I used public transportation more than I usually do." Participants used a 5-point Likert scale to report their behavior frequency in the past 12 months, ranging from 1 being "never" to 5 being "always." We combined all 17 items and used the average as the ERB score. The alpha reliability was .83 .

\section{Results}

\subsection{Nationality and Ethnicity Differences in Environmental Attitudes and Behaviours and} Political Attitudes

To test both $\mathrm{H} 1$ (the NZ sample will show more liberal political attitudes and more environmentally friendly attitudes and behaviors than the US sample) and $\mathrm{H} 2$ (the indigenous sample will show less system justification and more environmentally friendly attitudes and behaviors than the non-indigenous sample), we conducted a series 2X2 ANOVAs in which the two independent variables were nationality (NZ vs. US) and ethnicity (indigenous vs. non-indigenous). Dependent variables included two environmental beliefs (NEP and GCC belief), ERB, as well as two political attitudes (liberalism and perception of system justification). The F test results for these five ANOVAs are presented in Table 1.

Table 1. ANOVA results of nationality, ethnicity, and their interaction on NEP, GCC belief, ERB, system justification, and liberalism

\begin{tabular}{|l|l|l|l|l|}
\hline \multicolumn{5}{|c|}{ F value } \\
\hline & nationality & ethnicity & interaction & error $d f$ \\
\hline NEP & $23.43^{* *}$ & .37 & 1.16 & 298 \\
\hline GCC belief & $32.74 * *$ & 1.80 & .16 & 310 \\
\hline ERB & $7.87 * *$ & .13 & 3.00 & 286 \\
\hline System justification & .01 & $5.96 *$ & 1.60 & 305 \\
\hline Liberalism & $73.25^{* *}$ & $5.07 *$ & $12.67 * *$ & 312 \\
\hline
\end{tabular}

Note. $N=290-316$.

NEP-New Ecological Paradigm. GCC - Global Climate Change. ERB-Environmentally Responsible Behavior 


\section{Macrothink

$* p<.05, * * p<.01$, two-tailed

\subsubsection{NEP, GCC Belief, and ERB}

The ANOVA results showed a highly similar pattern for NEP, GCC belief, and ERB: nationality had a statistically significant main effect on NEP, GCC, and ERB, suggesting that compared to the US sample, the NZ sample embraced a stronger ecological worldview and were more likely to believe in GCC and participate in ERB. We present the means and standard deviations for NEP, GCC, and ERB by nationality in Table 2. These results provided support for H1. Ethnicity did not show a significant effect on any of the three dependent variables, which suggests that the indigenous and non-indigenous samples did not show statistically significant differences on NEP, GCC, and ERB. This result did not support H2. We also did not find a significant interaction between nationality and ethnicity on these three variables.

Table 2. Means and standard deviations for NEP, GCC belief, and ERB by nationality

\begin{tabular}{|l|l|l|l|r|}
\hline & \multicolumn{3}{|l|}{ New Zealand } & \multicolumn{2}{l|}{ U.S. } \\
\hline & Mean & SD & Mean & SD \\
\hline NEP & 3.73 & .50 & 3.36 & .54 \\
\hline GCC belief & 4.07 & .72 & 3.52 & .77 \\
\hline ERB & 2.88 & .56 & 2.62 & .58 \\
\hline
\end{tabular}

Note. $N=290-316$.

SD — Standard deviation. NEP—New Ecological Paradigm. GCC - Global Climate Change. ERB-Environmentally Responsible Behavior.

\subsubsection{Liberalism}

We found a statistically significant effect for nationality, ethnicity, and their interaction (see Figure 1), suggesting that overall, the NZ sample were more liberal than the US sample, which supported H1. The indigenous indivduals as a group were more conservative than the non-indigenous. However, these effects were qualified by a significant two-way interaction. Further t-tests indicated that that whereas the non-indigenous people $(M=2.76, S=.72)$ were more liberal than indigenous group $(M=2.26, S=.59)$ in US, $t(193)=4.07, p<.001$, the difference between the non-indigenous sample $(M=3.19, S=.69)$ and the indigenous sample $(M=3.30, S=.49)$ in NZ was not significant, $t(119)=-.97, p=.34$. 


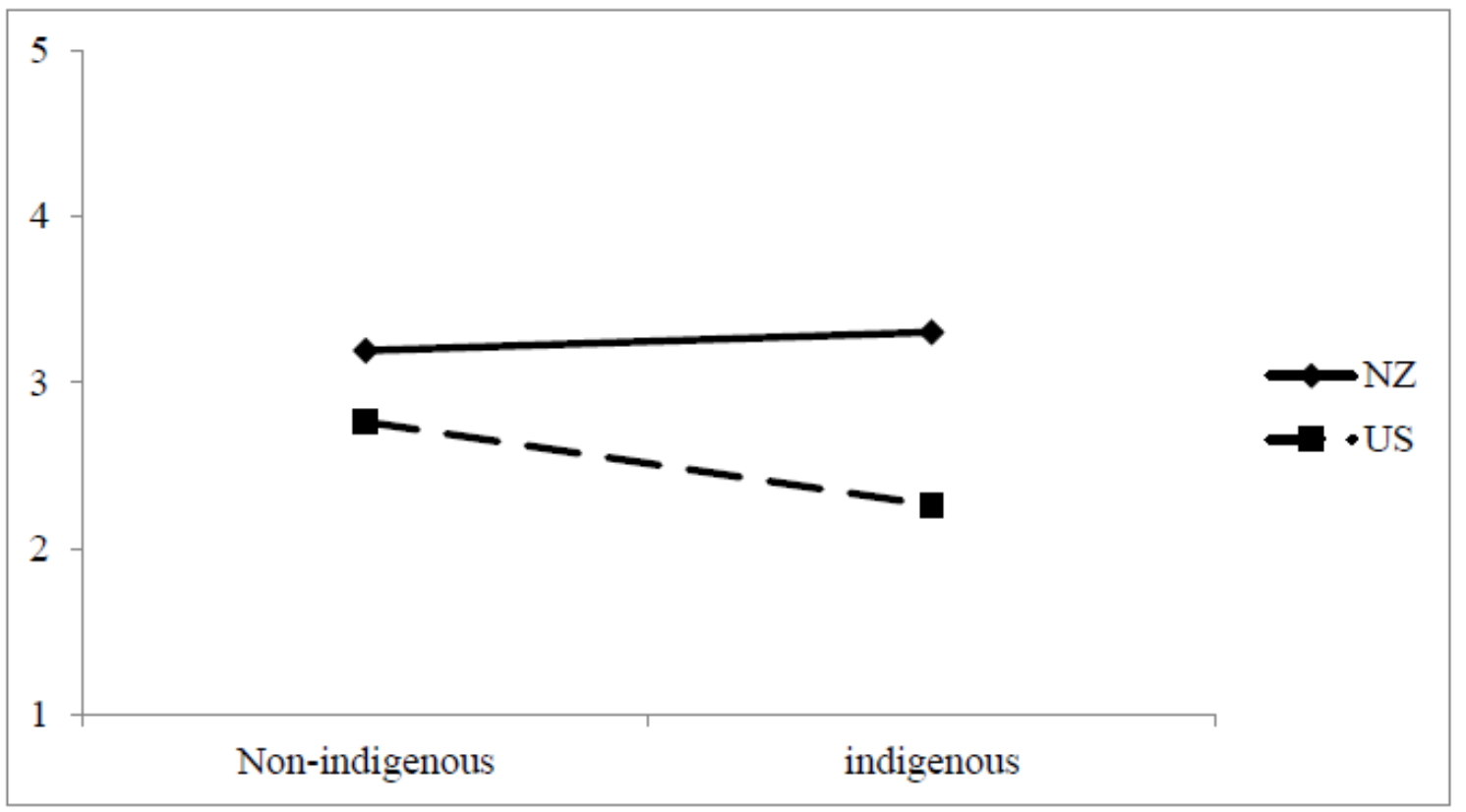

Figure 1 . The interaction effect between nationality and ethnicity on liberalism

\subsubsection{System Justification}

The ANOVA test revealed a significant main effect for ethnicity but not for nationality for system justification. This indicates that overall, the indigenous sample ( $M=4.54, S=1.19)$ had significantly less faith in the current political system than the non-indigenous sample did $(M=4.90, S=1.22)$. This provided partial support for $\mathrm{H} 2$. There was no significant difference in this perception between the NZ and US samples. Additionally, the interaction was not statistically significant.

\subsection{Predicting ERB from NEP, GCC, System Justification, and Liberalism}

\subsubsection{Zero-order Correlations}

We first examined the correlations between the five variables of interest: $N E P, G C C, E R B$, system justification, and liberalism (see Table 3). Overall, the constructs showed statistically significant, moderate-size intercorrelations except for system justification, which had weak correlations $(r s<.20)$ across the board. The strongest correlations tended to involve NEP and GCC. These correlations suggested that participants' environmental beliefs tended to go hand in hand with liberalism and ERB, which is in line with the mediation model where environmental beliefs mediate the association between liberalism and ERB. However, system justification was only weakly correlated with political attitudes, environmental attitudes, and environmental behaviors. 


\section{Macrothink \\ Environmental Management and Sustainable Development \\ ISSN 2164-7682 \\ 2021, Vol. 10, No. 1}

Table 3. Correlations of ERB, liberalism, system justification, NEP, and GCC belief

\begin{tabular}{|l|l|l|l|l|}
\hline & Liberalism & NEP & GCC belief & System justification \\
\hline ERB & $.17 * *$ & $.31 * * *$ & $.36 * * *$ & -.10 \\
\hline Liberalism & & $.30 * * *$ & $.44 * * *$ & $-.14 *$ \\
\hline NEP & & & $.30 * * *$ & $-.18 * *$ \\
\hline GCC & & & & -.10 \\
\hline
\end{tabular}

Note. $\mathrm{N}=286-317$.

NEP — New Ecological Paradigm. GCC — Global Climate Change. ERB — Environmentally Responsible Behavior.

$* p<.05, * * p<.01, * * * p<.001$, two-tailed

\subsubsection{Testing the Mediation Model}

Only liberalism was included in the proposed mediation model as the predictor because system justification was not signficantly corerlated with ERB and GCC. We conducted a mediation analysis using the statistical program JASP with maximum likelihood estimation to test the proposed model (Figure 2) in which liberalism is the predictor, ERB is the outcome, and both NEP and GCC are mediators of the effects of liberalism on ERB. The results showed that once NEP and GCC were added to the prediction of ERB, liberalism no longer had a significant direct effect on ERB (parameter estimate $=-.02, p=.629,95 \%$ confidence interval for the direct effect $=-.11$ to .07 ) but had significant indirect effects on ERB through NEP (parameter estimate $=.06, p<.001,95 \%$ confidence interval for the indirect effect $=.02$ to .09) and GCC (parameter estimate $=.10, p<.001,95 \%$ confidence interval for the indirect effect $=.05$ to .14 ). In other words, NEP and GCC together fully mediated the link between liberalism and ERB (see Figure 2 for path coefficients). This mediation model was able to account for $17 \%$ of the variance in ERB, which is considered a medium effect according to Cohen's (1988) criteria. These mediation results provided good support for H5, suggesting that the positive association between liberalism and ERB was primarily due to the fact that more liberal individuals are more likely to embrace an ecological worldview and believe in global climate change. 


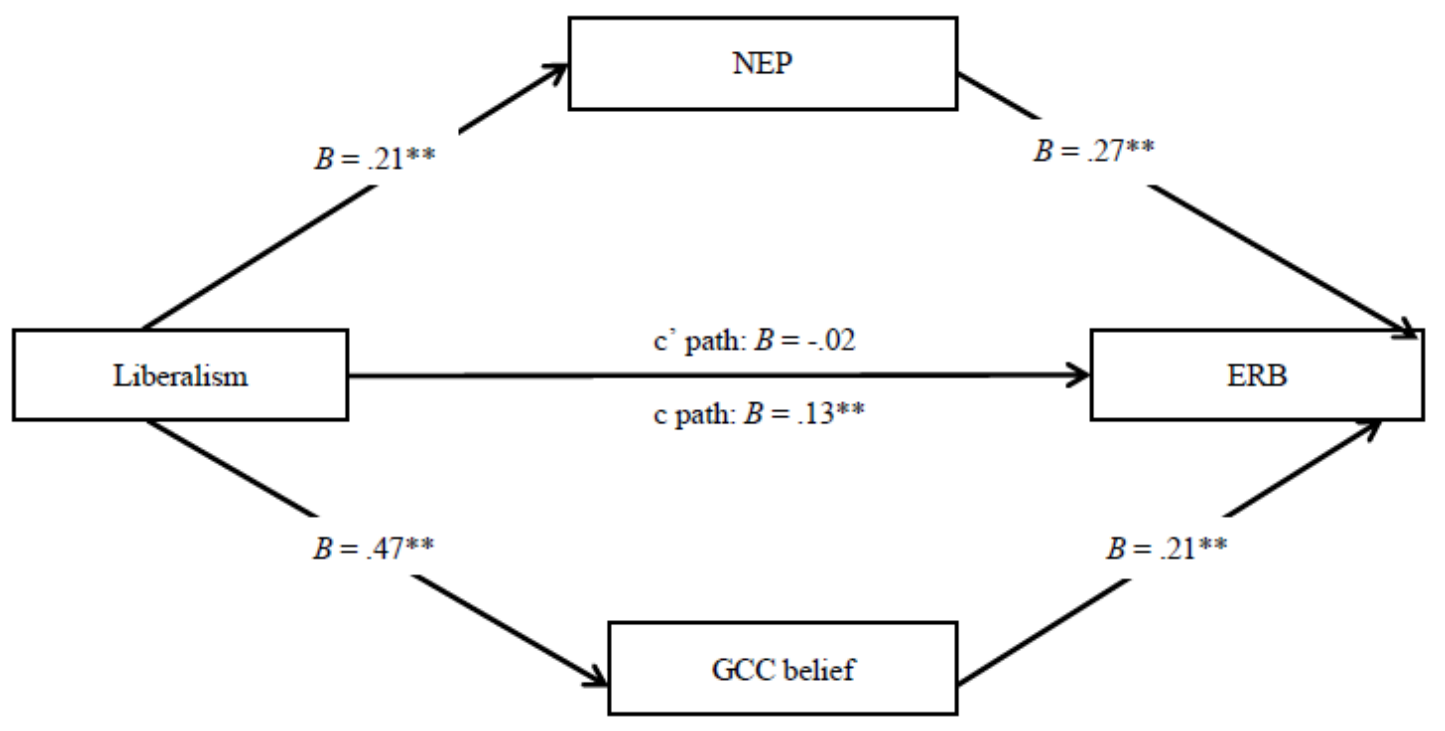

Figure 2. NEP and GCC mediate the association between liberalism and ERB

\section{Discussion}

This study was one of the first to conduct comparisons between a sample of indigenous vs. non-indigenous individuals in New Zealand and US on political attitudes as well as environmental beliefs and behaviors. The results supported our predictions that the NZ sample overall was politically more liberal and showed more environmentally friendly beliefs and behaviors in comparison to the US sample. As expected, the indigenous sample was significantly less likely to espouse system jusification than their non-indigenous counterpart. However, while we had anticipated that the indigenous sample would be more environmentally friendly, the indigenous and non-indigenous samples did not show signficant differences in environmental beliefs or practices.

Overall, these comparisons indicated that the differences between the US and NZ sample in this study were more robust than the cross-ethnicity differences between the indigenous and non-indigenous samples in political and environmental attitudes and behaviors. In fact, as shown in supplemental Table 1, posthoc analyses of comparing the 4 groups (Lumbee, US non-indigenous, Māori, European NZ) showed that the only variable that showed significant difference between the Māori and European New Zealander samples was system justification. The only signficant difference between the Lumbee and non-indigenous American samples was liberalism. However, the two indigenous samples in US and New Zealand showed signficant differences on liberalism, NEP, and GCC. The two non-indigeous groups in the two countries differed significantly on all variables except for system justification. Thus, it appears that in our study there were more signficant differences between the two nations than between the two ethnicities. It is possible that the overall culture within a nation has a strong, overarching effect influencing its citizens' perceptions and behaviors, regardless of ethnic background. In this specific case, NZ appears to fit a "clean and green" national image more than US does. It is important to keep in mind that given the limited sample size in the current 
study, these findings should be considered as preliminary until more conclusive evidence is reported.

Supplemental Table 1. Compare the four groups on NEP, GCC belief, ERB, system justification, and liberalism

\begin{tabular}{|l|l|l|l|l|}
\hline & European NZ & Maori & Non-indigenous US & Lumbee \\
\hline & $M(S D)$ & $M(S D)$ & $M(S D)$ & $M(S D)$ \\
\hline NEP & $3.74(.46) \mathrm{a}$ & $3.71(.57) \mathrm{a}$ & $3.33(.54) \mathrm{b}$ & $3.45(.51) \mathrm{b}$ \\
\hline GCC belief & $4.14(.71) \mathrm{a}$ & $3.97(.74) \mathrm{a}$ & $3.54(.74) \mathrm{b}$ & $3.45(.89) \mathrm{b}$ \\
\hline ERB & $2.94(.51) \mathrm{a}$ & $2.78(.64)$ & $2.59(.61) \mathrm{b}$ & $2.70(.42) \mathrm{b}$ \\
\hline System justification & $5.02(1.25) \mathrm{a}$ & $4.44(1.35) \mathrm{b}$ & $4.84(1.20)$ & $4.65(1.00)$ \\
\hline Liberalism & $3.19(.69) \mathrm{a}$ & $3.30(.49) \mathrm{a}$ & $2.76(.72) \mathrm{b}$ & $2.26(.59) \mathrm{c}$ \\
\hline
\end{tabular}

Note. $\mathrm{N}=290-316$. Means with different superscripts showed a statistically significant difference.

NEP_New Ecological Paradigm. GCC — Global Climate Change. ERB — Environmentally Responsible Behavior

The only noteworthy cross-ethnicity difference was that the indigenous sample had less faith in the current system than the non-indigenous sample. This disparity may reflect the history of political and cultural oppression experienced by indigenous groups in both nations. Surprisingly, indigenous groups did not display more favorable environmental beliefs or actions than non-indigenous groups. This finding seems to contradict the so-called "ecological noble Indian" stereotype wherein the natives are seen as the "original conservationists" (Redford, 1991). Nadasdy (2005) noted that while indigenous people tend to have tremendous reverence for earth and life, it may be inaccurate to assume that they are naturally more environmentally conscious for several reasons. First, some indigenous practices, although leading to ecologically favorable outcomes, may not be driven by environmental initiatives. Second, there are vast differences across different tribes within the indigenous community in terms of environmental awareness and protection. Finally, viewing indigenous peoples through the simplistic stereotype of "noble Indians" sets up unrealistic, and potentially damaging, expectations. Additionally, because indigenous people have their own traditional perceptions, standards, and environmental practices, an European-American framework of environmentalism may not be completely appropriate in evaluating their behaviors.

Our results showed that both NEP and GCC were not only significantly correlated with ERB, but were significant mediators of the link between liberalism and ERB. These findings replicated previous finding that suggested the central role of a person's ecological worldview in predicting environmental actions. Further, our findings highlighted the importance of GCC beliefs. Despite its narrow focus, GCC beliefs carry as much weight as a person's ecological worldview in predicting environmental actions. This finding is consistent with one of the conclusions from Hornsey et al.'s (2016) meta-analysis that GCC belief alone had a small to 
moderate effect on pro-environmental actions. Moreover, our mediation analysis showed that the link between liberalism and ERB was fully mediated by NEP and GCC. This full mediation suggested that the effect of liberal political ideology on environmental actions relies on holding an ecological worldview and believing in GCC. In other words, politically liberal individuals are unlikely to undertake environmental behaviors until they have developed a pro-environmental worldview and believe that GCC is occurring primarily through human activities. This has important implications for environmental education and environmental campaigns. Liberal views do not automatically lead to environmental actions. Pro-environmental beliefs are essential to transform liberalism into actual behaviors. Thus, education and outreach actions are a requisite component of motivating populations to engage in environmental behaviors.

Moreover, the finding that both NEP and GCC were significant mediators suggested that a broad ecological worldview such as NEP and a specific but salient belief such as one's stand on the GCC issue each serve distinctly different roles in promoting ERB. While the current study was unable to identify the exact roles that these two types of belief play in environmental actions, we speculate that a broad ecological worldview may be more predictive of support for general policy-based behaviors, whereas GCC belief may be more closely related to changes in specific actions. The more narrowly an issue is defined, the more likely it will be to engender suggestions for specific actions designed to address it. For example, water shortages are likely to produce calls for shorter showers and turning water off while brushing teeth, whereas an environmental worldview will be more likely to be predictive of broader regulatory policy measures to protect the environment. It would be useful for future research to explore the exact mechanisms by which NEP and GCC may lead to more frequent ERB.

Our hypotheses regarding the impact of system justification on environmental beliefs and ERB were largely unsupported. Namely, system justification was only weakly correlated with NEP but not significantly correlated with GCC or ERB. It was also only weakly associated with liberalism. This suggests that belief in the current system did not appear to be strongly associated with political ideology nor with environmental beliefs and actions in our sample. In other words, there was an apparent disconnect between system justification and all other variables. This was inconsistent with Feygina et al.'s (2010) finding suggesting that people who were more conservative showed more attachment to current system and were less interested in societal changes such as pro-environmental beliefs and behaviors. One possible main reason for this major discrepancy was the sample composition. While Feygina et al. (2010) relied on college samples recruited at several prestigious institutions that likely comprised primarily White, upper-class individuals, the current sample included mostly students from lower to middle-class families and a substantial amount of indigenous individuals. It is likely that some indigenous people, particularly Lumbee, may separate political struggles from environmental issues. Members of this tribe tend to espouse more conservative views and their political actions frequently align with the Republican party (Allot, 2017).

While the current findings add new valuable information to our understanding of political 
attitudes, environmental beliefs, and ERB, particularly by including a comparison between indigenous and non-indigenous samples in two nations, the study had several noteworthy limitations. First, the US indigenous sample primarily consisted of one American Indian tribe (Lumbee). The NZ indigenous sample included over 30 iwi; nevertheless it was far from representative of all Māori. It is important to note that indigenous tribes vary considerably in political orientation, environmental perceptions, and environmental practices (see Cowie et al., 2016). The results are by no means representative of all indigenous peoples, but rather serve as a call for more research attention to indigenous issues. Additionally, the NZ sample and US sample were each recruited at one university. The results would have likely been different had another institution, or a different region in US or NZ, or different countries been approached. Second, all participants were enrolled college students and thus the sample was restricted in age, education, and life experiences. Finally, the sample size was only modest, particularly the indigenous sample. We hope the current findings, while limited in sampling, will stimulate strong enthusiasm in more research to improve our understanding of environmental beliefs and behaviors in different cultures, particularly those underrepresented in the current mainstream research.

\section{Conclusions}

Actions of humans, including all nations and ethnicities, play an important role in our earth's health. Human actions have had immense impacts on the world's ecosystems. It is extremely important and necessary for humans to address the problems we have caused and reduce our individual and societal impacts. Education and encouragement of environmental stewardship is imperative. To accomplish this, it is critical to acquire a good understanding of environmental beliefs and the mechanisms of environmental behaviors in all cultures. This study expanded previous research by examining environmental beliefs and behaviors from a cross-cultural perspective. Namely, it provided a comparison that indicated systematic differences between the NZ and US sample in political ideology, environmental beliefs, and ERB. The current study also presented a comparison between indigenous and non-indigenous samples. The results indicated that these two samples only differed in system justification. These findings are useful in that environmental educators must recognize the commonalities and disparities across different populations and strategize accordingly when working with them. Environmental education should be as diverse as the cultures being addressed. Finally, the current study provided good evidence indicating that environmental worldviews such as NEP and stances on salient environmental issues such as GCC are channeling liberal ideology into ecologically responsible behaviors. This finding shed light on productive routes to increase public engagement in environmental actions.

\section{References}

Allot, D. (2017). How Donald Trump won America's most racially diverse rural county. [Online] Available: http://2020.washingtonexaminer.com/robeson-county/donald-trump-wonlumbee-tribe-racially-diverse/

Bamberg, S., \& Moser, G. (2007). Twenty years after Hines, Hungerford, and Tomera: A new meta-analysis of psycho-social determinants of pro-environmental behaviour. Journal of 
Environmental Psychology, 27, 14-25. https://doi.org/10.1016/j.jenvp.2006.12.002

Bechtel, R. B., Verdugo, V. C., \& Pinheiro, J. (1999). Environmental belief systems: United States, Brazil, and Mexico. Journal of Cross-Cultural Psychology, 30, 122-28. https://doi.org/10.1177/0022022199030001008

Boiral, O., Raineri, N., \& Talbot, D. (2018). Managers' citizenship behaviors for the environment: A developmental perspective. Journal of Business Ethics, 149, 395-409. https://doi.org/10.1007/s10551-016-3098-6

Buttel, F. H., \& Flinn, W. L. (1976). Economic growth versus the environment: Survey evidence. Social Science Quarterly, 57, 410-420.

Caron, J. A. (1989). Environmental perspectives of blacks: Acceptance of the "New Environmental Paradigm”. The Journal of Environmental Education, 20, 21-26. https://doi.org/10.1080/00958964.1989.9942785

Clark, B. (2002). The indigenous environmental movement in the United States transcending borders in struggles against mining, manufacturing, and the capitalist state. Organization and Environment, 15, 410-442. https://doi.org/10.1177/1086026602238170

Cohen, J. (1988). Statistical power analysis for the behavioral sciences (2nd ed.). Hillsdale, NJ: Lawrence Erlbaum Associates, Publishers.

Cook, J., Nuccitelli, D., Green, S. A., Richardson, M., Winkler, B., Painting, R., Way, R., Jacobs, P., \& Skuce, A. (2013). Quantifying the consensus on anthropogenic global warming in the scientific literature. Environmental Research Letters, 8, 1-7.

https://doi.org/10.1088/1748-9326/8/2/024024

Cordano, M., Welcomer, S. A., \& Scherer, R. F. (2003). An analysis of the predictive validity of the New Ecological Paradigm Scale. The Journal of Environmental Education, 34, 22-28. https://doi.org/10.1080/00958960309603490

Cowie, L. J., Greaves, L. M., Milfont, T. L., Houkamau C. A., \& Sibley, C. G. (2016). Indigenous identity and environmental values: Do spirituality and political consciousness predict environmental regard among Māori? International Perspectives in Psychology: Research, Practice, Consultation, 5, 228-244. https://doi.org/10.1037/ipp0000059

Coyle, F., \& Fairweather, J. (2005). Challenging a place myth: New Zealand's clean green image meets the biotechnology revolution. Area, 37, 148-158.

https://doi.org/10.1111/j.1475-4762.2005.00617.x

Dunlap, R., Xiao, C., \& McCright, A. (2001). Politics and environment in America: Partisan and ideological cleavages in public support for environmentalism. Environmental Politics, 10, 23-48. https://doi.org/10.1080/714000580

Dunlap, R. E., \& Van Liere, K. D. (1978). The "new environmental paradigm": A proposed measuring instrument and preliminary results. Journal of Environmental Education, 9, 10-19. https://doi.org/10.1080/00958964.1978.10801875 


\section{Macrothink}

Environmental Management and Sustainable Development

ISSN 2164-7682

2021, Vol. 10, No. 1

Dunlap, R., Van Liere, K., Mertig, A., \& Jones, R. (2000). Measuring endorsement of the New Ecological Paradigm: A revised NEP scale. Journal of Social Issues, 56, 425-442. https://doi.org/10.1111/0022-4537.00176

Feygina, I., Jost, J., \& Goldsmith, R. (2010). System justification, the denial of global warming, and the possibility of "system-sanctioned change". Personality and Social Psychology Bulletin, 36, 326-338. https://doi.org/10.1177/0146167209351435

Furman, A. (1998). A note on environmental concern in a developing country: Results from an Istanbul survey. Environment and Behavior, 30, 520-34.

https://doi.org/10.1177/001391659803000406

Gooch, G. D. (1995). Environmental beliefs and attitudes in Sweden and the Baltic States. Environment and Behavior, 27, 513-39. https://doi.org/10.1177/0013916595274004

Growth and Innovation Advisory Board. (2004). Research on growth and innovation: Research summary. [Online] Available:

http://www.giab.govt.nz/work-programme/growth/researchsummary/index.html

Hawcroft, L. J., \& Milfont, T. L. (2010). The use (and abuse) of the new environmental paradigm scale over the last 30 years: A meta-analysis. Journal of Environmental Psychology, 30, 143-158. https://doi.org/10.1016/j.jenvp.2009.10.003

Hawke, S. M. (2012). Water literacy: An otherwise, active and cross-cultural approach to pedagogy, sustainability and human rights. Continuum, 26, 235-247.

https://doi.org/10.1080/10304312.2012.664120

Hawkins, S., Yudkin, D., Juan-Torres, M., \& Dixon, T. (2018). Hidden tribes: A study of America's polarized landscape. New York: More in Common.

https://doi.org/10.31234/osf.io/xz25v

Hawthorne, M., \& Alabaster, T. (1999). Citizen 2000: Development of a model of environmental citizenship. Global Environmental Change, 9, 25-43.

https://doi.org/10.1016/S0959-3780(98)00022-3

Hines, J. M., Hungerford, H. R., \& Tomera, A. N. (1986/87). Analysis and synthesis of research on responsible environmental behavior: A meta-analysis. Journal of Environmental Education, 18, 1-8. https://doi.org/10.1080/00958964.1987.9943482

Hornsey, M. J., Harris, E. A., Bain, P. G., \& Fielding, K. S. (2016). Meta-analyses of the determinants and outcomes of belief in climate change. Nature Climate Change, 6, 622-627. https://doi.org/10.1038/nclimate2943

Hornsey, M. J., Harris, E. A., \& Fielding, K. S. (2018). Relationships among conspiratorial beliefs, conservatism and climate scepticism across nations. Nature Climate Change, 8, 614-620. https://doi.org/10.1038/s41558-018-0157-2

Hoxie, F. E. (1984). A Final Promise: The Campaign to Assimilate the Indians, 1880-1920. Lincoln: University of Nebraska Press. 


\section{Macrothink}

Environmental Management and Sustainable Development

ISSN 2164-7682

2021, Vol. 10, No. 1

Hsu, A. et al. (2016). 2016 Environmental Performance Index. New Haven, CT: Yale University. [Online] Available: http://epi.envirocenter.yale.edu

Hughey, K. F. D., Kerr, G. N., \& Cullen, R. (2016). Public perceptions of New Zealand's environment: 2016. EOS Ecology, Christchurch.

Hutching, G., \& Walrond, C. (2007). Marine conservation: Mäori and the sea. In Te Ara - The Encyclopedia of New Zealand. [Online] Available: http://www.teara.govt.nz/EarthSeaAndSky /OceanStudyAndConservation/MarineConservation/1/en

Johnson, C. Y., Bowker, J. M., \& Cordell, H. K. (2004). Ethnic variation in environmental belief and behavior: An examination of the new ecological paradigm in a social psychological context. Environment and Behavior, 36, 157-186. https://doi.org/10.1177/0013916503251478

Jost, J. T., \& Hunyady, O. (2005). Antecedents and consequences of system-justifying ideologies. Current Directions in Psychological Science, 14, 260-265.

https://doi.org/10.1111/j.0963-7214.2005.00377.x

Jost, J. T., Ledgerwood, A., \& Hardin, C. D. (2008). Shared reality, system justification, and the relational basis of ideological beliefs. Social and Personality Psychology Compass, 2, 171-186. https://doi.org/10.1111/j.1751-9004.2007.00056.x

Jost, J. T., Liviatan, I., van der Toorn, J., Ledgerwood, A., Mandisodza, A., \& Nosek, B. A. (2009). System justification: How do we know it's motivated? In R. Bobocel et al. (Eds.), The psychology of justice and legitimacy: The Ontario symposium (Vol. 11). Hillsdale, NJ: Lawrence Erlbaum.

Kay, A. C., \& Jost, J. T. (2003). Complementary justice: Effects of "poor but happy" and "poor but honest" stereotype exemplars on system justification and implicit activation of the justice motive. Journal of Personality and Social Psychology, 85, 823-837.

https://doi.org/10.1037/0022-3514.85.5.823

Kerr, G. N., Hughey, K. F. D., \& Cullen, R. (2016). Ethnic and immigrant differences in environmental values and Behaviors. Society and Natural Resources, 29, 1280-1295.

https://doi.org/10.1080/08941920.2016.1195029

Lewis, D. (1995). Native Americans and the environment: A survey of twentieth-century issues. American Indian Quarterly, 19, 423-50. https://doi.org/10.2307/1185599

Leiserowitz, A., Maibach, E., Rosenthal, S., Kotcher, J., Ballew, M., Goldberg, M., \& Gustafson, A. (2018). Climate change in the American mind: December 2018. Yale University and George Mason University. New Haven, CT: Yale Program on Climate Change Communication.

Leiserowitz, A., Maibach, E., Roser-Renouf, C., \& Hmielowski, J. D. (2012) Climate change in the American Mind: Americans'global warming beliefs and attitudes in March 2012. Yale University and George Mason University. New Haven, CT: Yale Project on Climate Change Communication. https://doi.org/10.2139/ssrn.2298705 


\section{Macrothink}

Environmental Management and Sustainable Development

ISSN 2164-7682

2021, Vol. 10, No. 1

Luo, S. (2009). Partner selection and relationship satisfaction in early dating couples: The role of couple similarity. Personality and Individual Differences, 47, 133-138.

https://doi.org/10.1016/j.paid.2009.02.012

Lumbee Tribe of North Carolina. (2012). Lumbee Recognition. [Online] Available:

http://www.lumbeetribe.com/.

McDonnell, J. A. (1991). The Dispossession of the American Indian, 1887-1934. Bloomington: Indiana University Press.

Michell, H. (2005). Nehithewak of Reindeer Lake, Canada: Worldview, epistemology and relationships with the natural world. Australian Journal of Indigenous Education, 34, 33-43. https://doi.org/10.1017/S132601110000394X

Milfont, T. L., \& Schultz, P. W. (2016). Culture and the natural environment. Current Opinion in Psychology, 8, 194-199. https://doi.org/10.1016/j.copsyc.2015.09.009

Mobley, C., Vagias, W. M., \& DeWard, S. L. (2010). Exploring additional determinants of environmentally responsible behavior: The influence of environmental literature and environmental attitudes. Environment and Behavior, 42, 420-447.

https://doi.org/10.1177/0013916508325002

Nadasdy, P. (2005). Transcending the debate over the ecologically noble Indian: Indigenous peoples and environmentalism. Ethnohistory, 52, 291-331.

https://doi.org/10.1215/00141801-52-2-291

Nash, R. F. (2001). Wilderness and the American mind. New Haven and London: Yale University Press.

Noe, F. P., \& Snow, R. (1990). Hispanic cultural influence on environmental concern. The Journal of Environmental Education, 21, 27-34.

https://doi.org/10.1080/00958964.1990.9941928

Olli, E., Grendstad, G., \& Wollebaek, D. (2001). Correlates of environmental behaviors: Bringing back social context. Environment and Behavior, 33, 181-208.

https://doi.org/10.1177/0013916501332002

O'Regan, H. (2012). The fate of customary language: Te Reo Māori 1900 to the present. In D. Keenan (Ed.), Huia histories of Māori. Wellington, New Zealand: Huia.

Pierce, J. C., Lovirch, N. P., Tsurutani, T., \& Abe, T. (1987). Environmental belief systems among Japanese and American elites and publics. Political Behavior, 9, 139-59.

https://doi.org/10.1007/BF00987303

Ponting, C. (1991). A green history of the world: The environment and the collapse of great civilizations. New York: Penguin.

Prucha, F. P. (1984). The Great Father: The United States Government and the American Indians. Lincoln: University of Nebraska Press. 


\section{Macrothink}

Environmental Management and Sustainable Development

ISSN 2164-7682

2021, Vol. 10, No. 1

Rangihau, J. (1992). Being Māori. In M. King (Ed), Te ao hurihuri: Aspects of Māoritanga. Auckland, New Zealand: Reed Publishing.

Redford, K. (1991). The ecologically noble savage. Cultural Survival Quarterly, 15, 46-48.

Roberts, M., Norman, W., Minhinnick, N., Wihongi, D., \& Kirkwood, C. (1995). Kaitiakitanga: Māori perspectives on conservation. Pacific Conservation Biology, 2, 7-20. https://doi.org/10.1071/PC950007

Schultz, P. W. (2002a). Environmental attitudes and behaviors across cultures. In W. J. Lonner, D. L. Dinnel, S. A. Hayes \& D. N. Sattler (Eds.), Online Readings in Psychology and Culture (Unit 8, Chapter 4). Bellingham: Western Washington University, Department of Psychology, Center for Cross-Cultural Research. https://doi.org/10.9707/2307-0919.1070

Schultz, P., \& Zelezny, L. (1998). Values and pro-environmental behavior: A five-country survey. Journal of Cross-Cultural Psychology, 29, 540-58.

https://doi.org/10.1177/0022022198294003

Sivek, D. J., \& Hungerford, H. (1989/1990). Predictors of responsible behavior in members of three Wisconsin conservation organizations. The Journal of Environmental Education, 21, 35-40. https://doi.org/10.1080/00958964.1990.9941929

Smith-Sebasto, N. J., \& D'Costa, A. (1995). Designing a Likert-type scale to predict ERB in undergraduate students: A multistep process. The Journal of Environmental Education, 27, 14-20. https://doi.org/10.1080/00958964.1995.9941967

Snider, A. G., Luo, S., \& Fusco, E. (2018). Predicting college students' environmentally responsible behavior from personality, political attitudes, and place attachment: A synergistic model. Journal of Environmental Studies and Sciences, 8, 290-299.

https://doi.org/10.1007/s13412-018-0497-2

UNCP College Portrait, (2012). Undergraduate snapshot. [Online] Available:

http://www.collegeportraits.org/NC/UNCP/print

University of North Carolina Pembroke. (2012). About UNCP. [Online] Available:

http://www.uncp.edu/uncp/about/index.htm

Waikato University. (2012). Waikato facts and figures. [Online] Available:

http://www.waikato.ac.nz/about/facts.shtml.

White, N. (2010). Indigenous Australian women's leadership: Stayin' strong against the postcolonial tide. International Journal of Leadership in Education, 13, 7-25.

https://doi.org/10.1080/13603120903242907

Williams, D. (2001). Crown policy affecting Māori knowledge systems and cultural practice. Wellington, New Zealand: Waitangi Tribunal Publication.

Wiidegren, O. (1998). The new environmental paradigm and personal norms. Environment and Behavior, 30, 75-100. https://doi.org/10.1177/0013916598301004 


\section{Macrothink}

Environmental Management and Sustainable Development

ISSN 2164-7682

Xiao, C., \& Dunlap, R. E. (2007). Validating a comprehensive model of environmental concern cross-nationally: A U.S.-Canadian comparison. Social Science Quarterly, 88, 471-493. https://doi.org/10.1111/j.1540-6237.2007.00467.x

Xiao, C., Dunlap, R. E., \& Hong, D. (2019). Ecological worldview as the central component of environmental concern: Clarifying the role of the NEP. Society \& Natural Resources, 32, 53-72. https://doi.org/10.1080/08941920.2018.1501529

\section{Copyright Disclaimer}

Copyright for this article is retained by the author(s), with first publication rights granted to the journal.

This is an open-access article distributed under the terms and conditions of the Creative Commons Attribution license (http://creativecommons.org/licenses/by/4.0/). 